\title{
Deletion in Syndrome Compounds Perspective Antarah Bin Shaddad: An applied grammatical study
}

\author{
Faiz Syu'aib Adam \\ University of Islam Madinah Arab Saudi \\ fshuaib3@gmail.com
}

Received: 23-12-2020

\begin{abstract}
The deletion in the syndromic compounds is a syntactic phenomenon that deals with the syntactic changes that occur to the Arabic sentence in deleting one of the compounds, and the compounds associated with this concept are those terms that the owner does not separate from the other, And its deletion is one of the characteristics of the Arabic language, the structure of the economy in the composition, and the structure of that deletion builds on several purposes and grammatical errors that suggest and summarize that. The research deals with these compounds contained in the commentary of Antarah bin Shaddad, who is one of the knights 'poets from the pre-Islamic era, because of the large number of these omissions in this comment.
\end{abstract}

Keywords: Antarah Bin Shaddad; Syndrome Compounds.

\section{ملخص}

الحذف في المركبات المتلازمة ظاهرة نحوية تعالج التغيرات الإعرابية التي تحدث للجملة العربية في حذف إحدى المركبات، والمركبات المتلازمة هذا المفهوم هي تلك المصطلحات التي لا ينفك صاحبها عن الآخر، فهو يكون معه بشكل تلازمي، وحذفها من خصائص اللغة العربية، وينبي تحت ذلك الحذف عدة أغراض وعلل نهوية توحي وتوجز ذلك، فالبحث تناول هذه المركبات الواردة في معلقة عننزة بن شداد، وهو أحد الشعراء الفرسان

$$
\text { من شعراء العصر الجحاهلي، لكثرة هذه المخذوفات في هذه المعلقة. }
$$

(C) 2021 Faiz Syu'aib Adam

(c) (i) (2)

This work is licensed under a Creative Commons Attribution-ShareAlike 4.0 International License.

المقدمة

عنوان البحث كما هو موضح هو: الحذف في المركبات المتلازمة في معلقة عننزة بن شداد, دراسة

نهوية تطبيقية، يتكون البحث من جانبين أساسيين، وهما : الجانب النظري وهو تعرف لعناصر الموضوع

من الحذف والنزكيب ومعنى كل مصطلح من اللغوي والاصطلاحي، ثم الجانب التطبيقي وهو الدراسة في

صميم البحث حيث يشتمل على إيراد البيت الموجود فيه الشاهد، ثم تعيين موطن الشاهد، ثم دراسة

الشاهد مستعينا بكتب النحو، وبيان خحلاف النحاة فيه إن وجد، وإن كان في البيت أكثر من رواية إن

وجد، تطرقت للبيان عنه، فهذه هي وظيفت في المقالة. 
ومشكالات البحث هي الافنزاصيات التي قد تقنزح للبحث ويمكن تلخيصها في النقاط التالية: عدم وضوح الشاهد في البيت، تعدد طرق تخريج الشاهد والدراسة عنه، صعوبة البحث عن آراء النحاة في المسألة، كثرة المركبات المتلازمة في المعلقة. والغرض من كتابة هذه المفالة هو الاعتناء لنزاث العربي القديم، إذ المعلقات هلا شأن كبير في هردهات الدراسات العربية، وخاصة في بناء القواعد النحوية، والتوسع في الإحاطة لكثير من اللهجات العربية الفصيحة، فهي جديرة هذه الدراسة، ثم كثرة المركبات المتلازمة في الدراسات النحوية جعلني متشوقا لهذه المقال لاستخراج هذه الأشكال المركبة في هذه المعلقة.

$$
\text { نتائج البحث ومناقشتها }
$$

حذف: قطف الشيء من الطرف كما يحذف طرف ذنب الشاة(1)، والحذف: الرمي عن جانب والضرب عن جانب، وتقول: حذفني فلان بجائزة أي: وصلين، وحذفه لسيف: على ما فسرته من الضرب عن جانب، والحذف: ضرب من الغنم السود الصغار، واحدها حذفة.

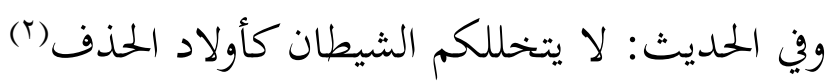
قال الشاعر:

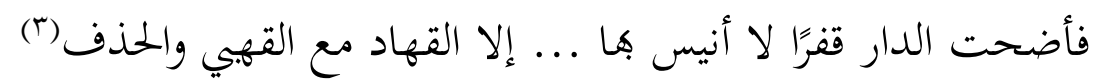
قال أبو عبيد: الحذف هي هذه الغنم الصغار الحجازية واحدةها حذفة، ويقال لها: النقد أيضا. قال: وقد فسر الحذف في بعض الرواية أها ضأن سود جرد صغار تكون ليمن.(؛)، حذف الشئ: إسقاطه، يقال: حذفت من شعري ومن ذنب الدابة، أي أخذت، والحذافة: ما حذفته من الأديم وغيره،

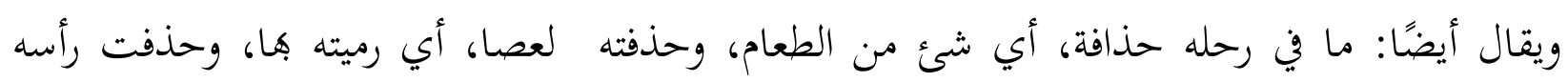

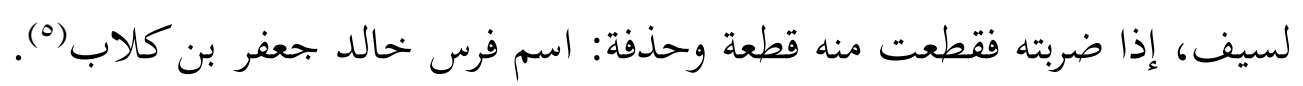

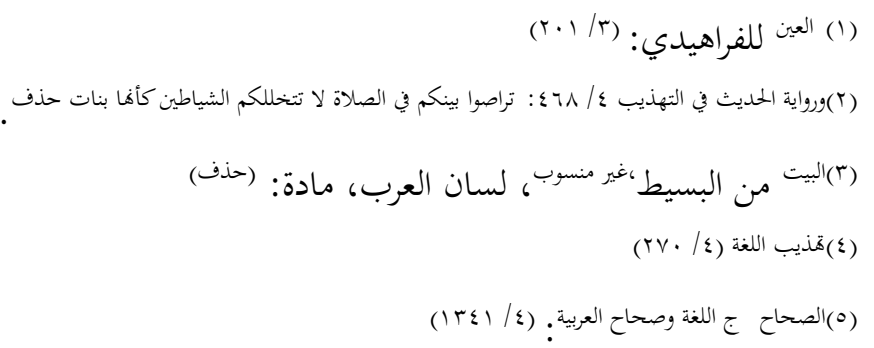


Faiz Syu'aib Adam : Deletion in Syndrome Compounds Perspective Antarah Bin Shaddad........

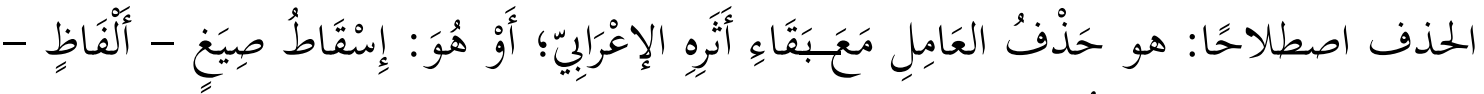

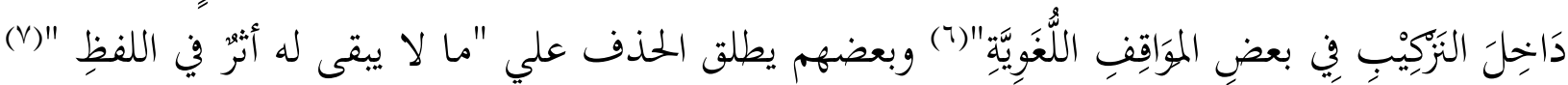

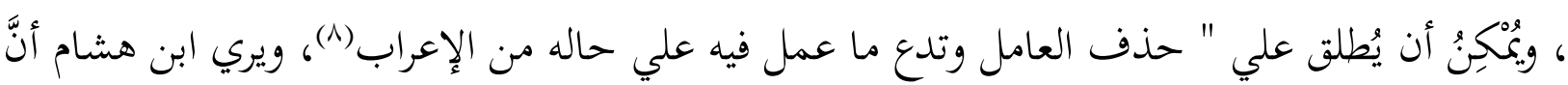

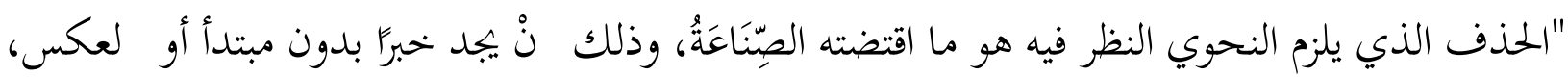

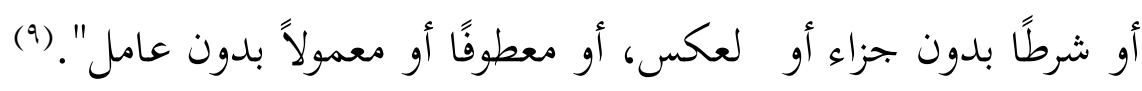

مفهوم النزكيب

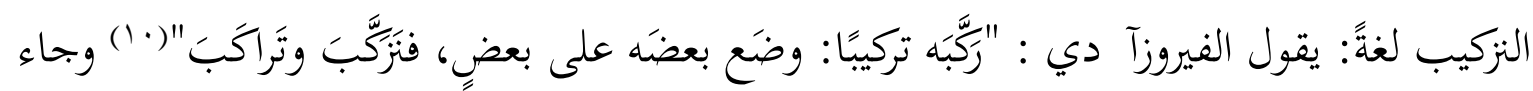

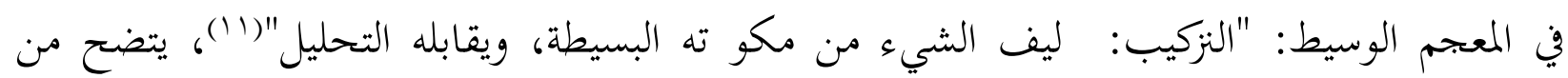

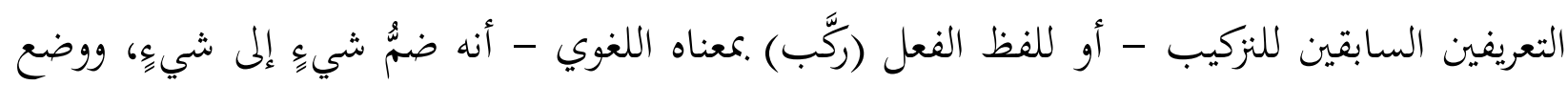
شيءٍ على شي؛؛ حيث يَصيران في سياق واحد ولحمةٍ واحدة. النزكيب اصطلاحًا: يقول أبو علي الفارسي : "الاسم تلفئ مع الاسم، فيكون كلامًا مفيدًا؛ كقولنا:

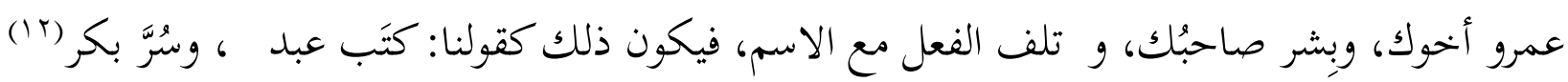

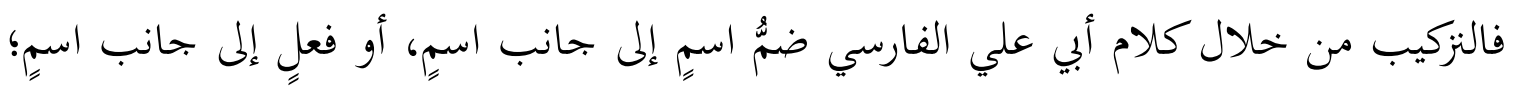

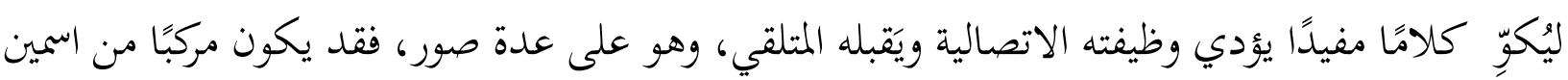

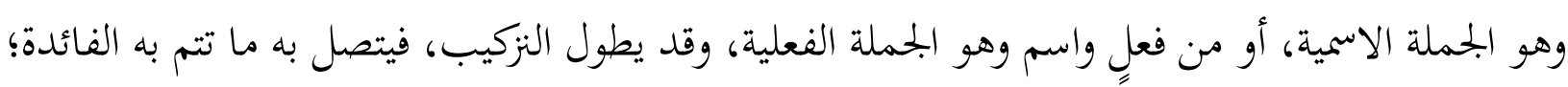
كشبه الجملة - من الظرف والجار والبمرور - والمفاعيل نواعها، وغيرها من المكمالات التي وإن كانت

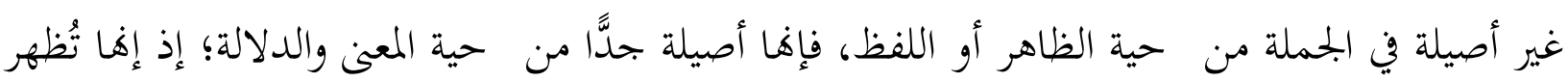
مَن وقَع عليه فعلُ الفاعل، أو تُوضِح حاله وهيئهن، أو غايةً فِعله.

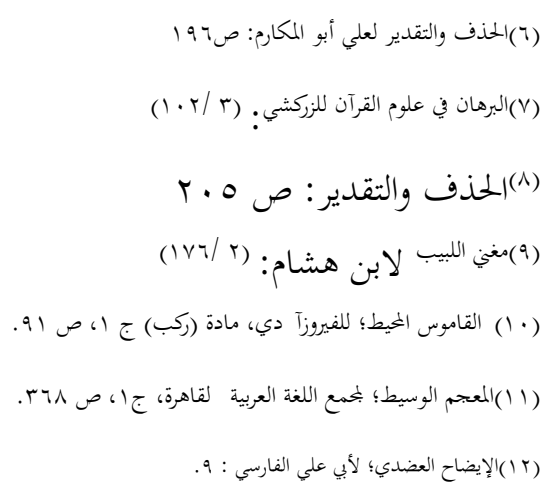


ومن ثم اضطرت اللغة العربية للتغاير بين هذه المركبات على شكل ما وردت عليه، فهناك النزكيب

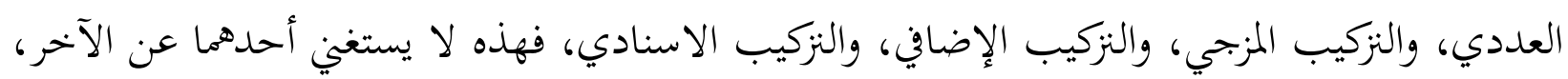

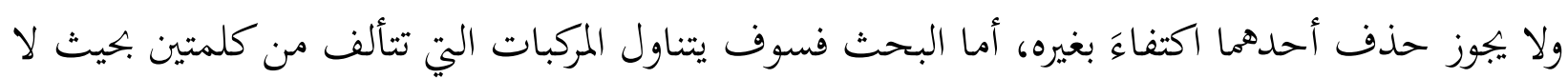

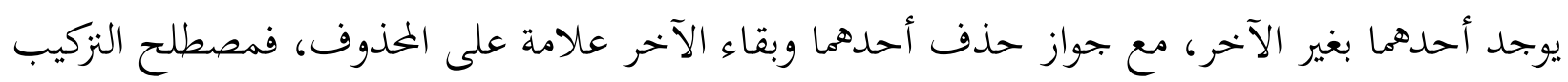

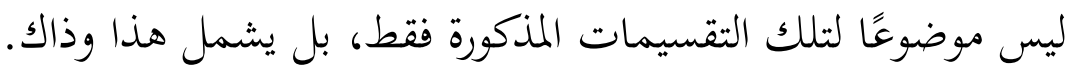

مفهوم التلازم

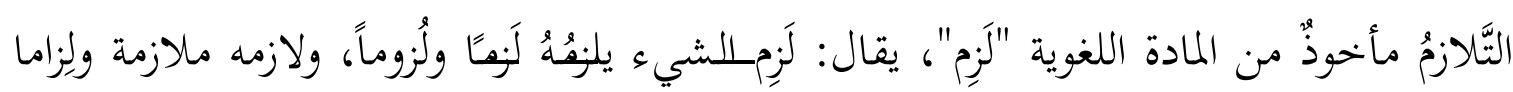

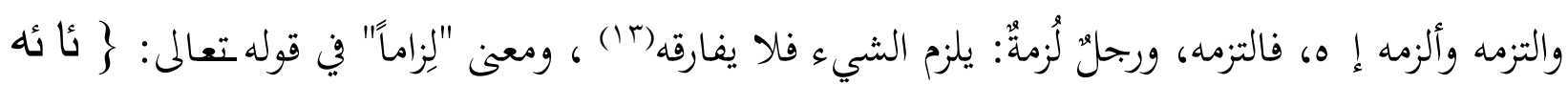

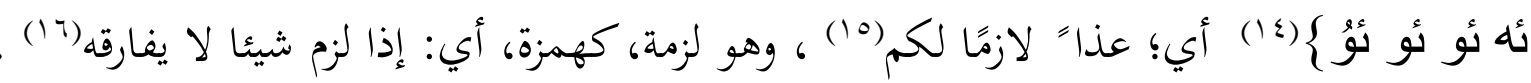

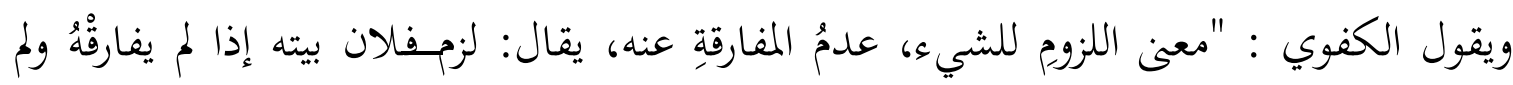

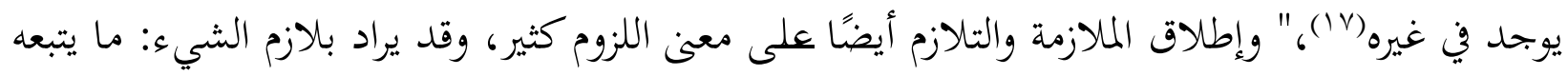

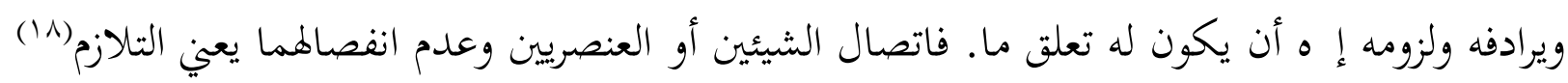

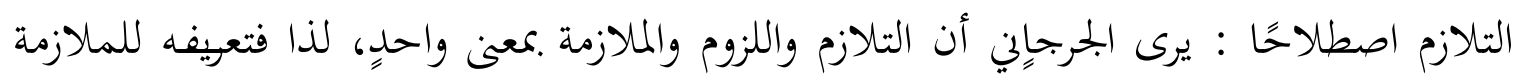

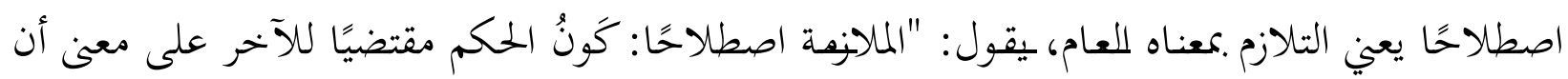

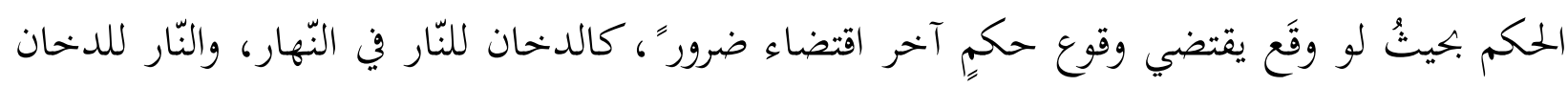
في الليل" (19) و تعُد الملازمةً المطلقة" هي كونُ الشيء مقتضيًا للآخر، والشيءُ الأول هو المسمى لملمومج،

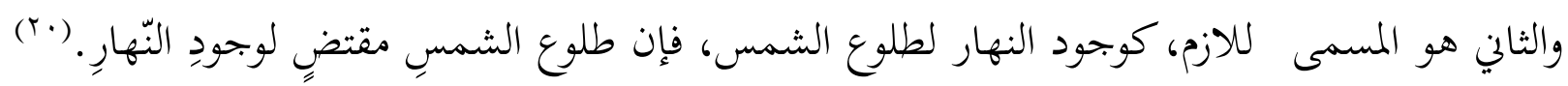

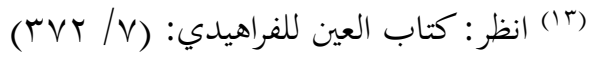

$$
\begin{aligned}
& \text { VV: (ع (1) }
\end{aligned}
$$

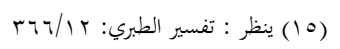

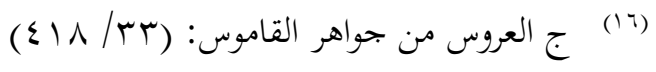

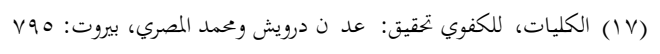

$$
\begin{aligned}
& \text { VAT: التعريفات، للحرجاني }
\end{aligned}
$$

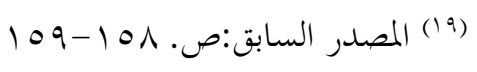

$$
\begin{aligned}
& \text { 109. } 109 .
\end{aligned}
$$




\section{الدراسة التطبيقية عن الحذف في معلقة عننزة}

ومن شواهد حذف المبتدأ في معلقة عننزة ما يلي :

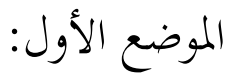

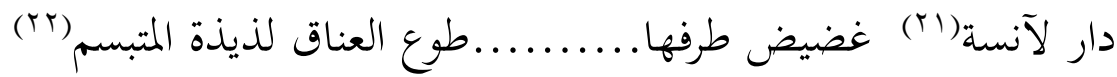
الشاهد فن البيت هو حذف المبتدأ في قوله: دار، هو خبر لمبتدأ محذوف تقديره: هي دار، والغرض من

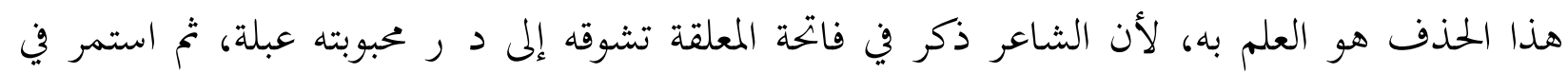
وصف هذه الد ر بذكر عدة صفات لما متغزلاً بذكر أطلال محبوبته، فحذف الخبر في هذا البيت إشارةً إلى أنه سبق ما يدل عليه. الموضع الثاني:

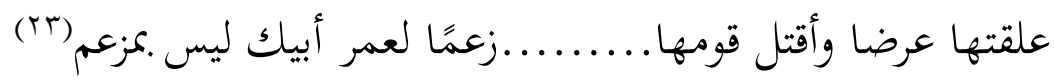

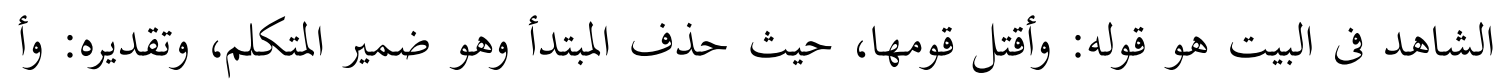

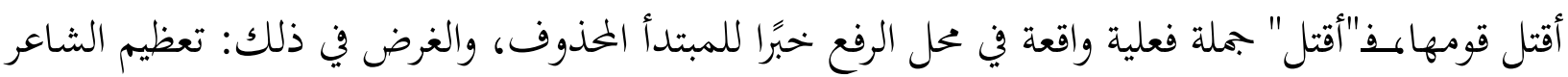
نفسه وإبراز فروسيته، فحذف المبتدأ علامة على ظهوره حيث لا يحتاج إلى ذكر، لأن جملة "أقتل" تشتمل على هذا الضمير الذي هو الفاعل المستنز للفعل.

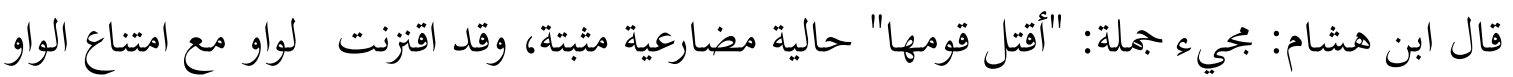
في ذلك، والتقدير: وقتلت قومها؛ وذلك ليتناسب المتعاطفان، فذلك أولى من عدم التناسب، الواو عاطفة والمضارع مؤول لماضي، وقيل: واو الحال والمضارع خبر لمبتدأ محذوف، أي: وأ أقتل (צُج). ومن مواضع حذف خبر المبتدأ في معلقة عننزة ما يلي:

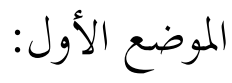

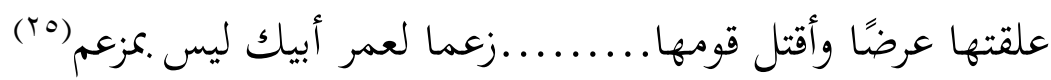
(1) (1) هي الفتاة الطيبة النفس التي لم تتزوج، غضيض: العين:

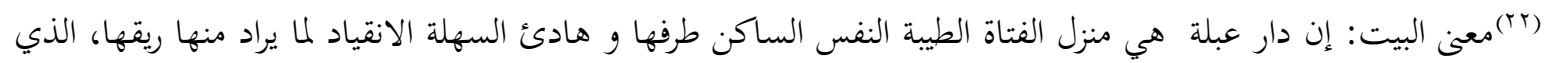

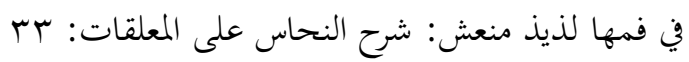

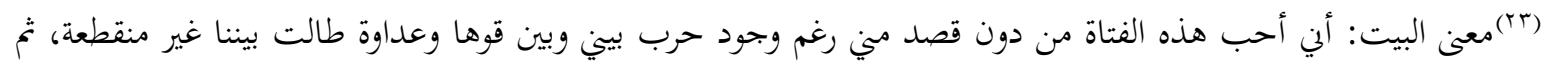

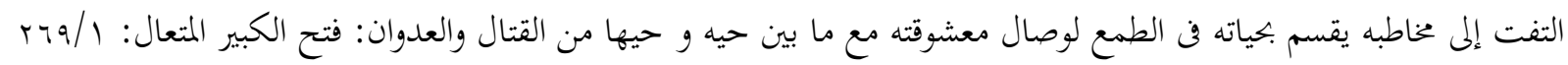

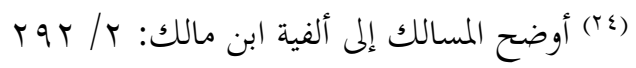

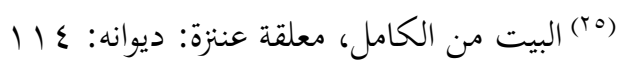


الشاهد في البيت هو قوله: لعمرك، هو مبتدأ، والكاف ضمير متصل في محل الجر لإضافة،

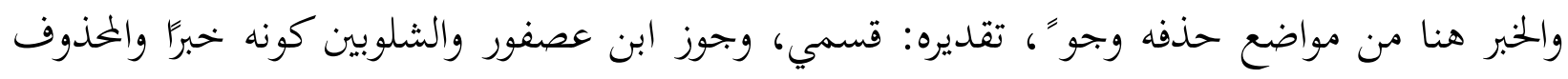

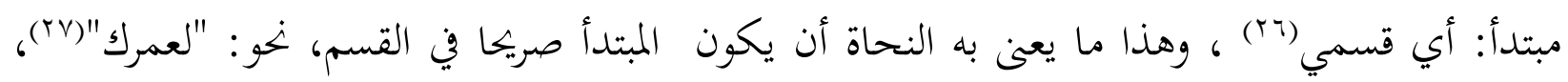

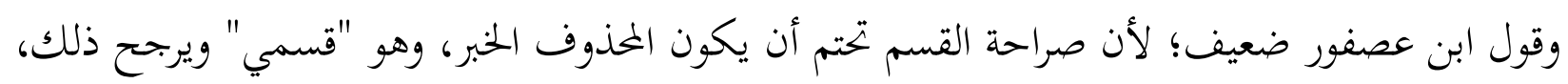

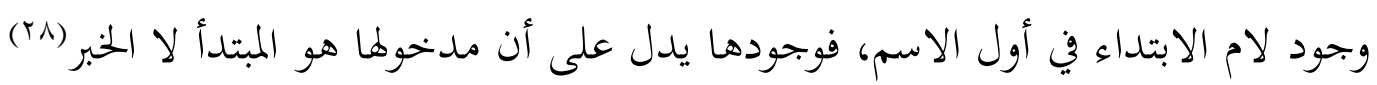

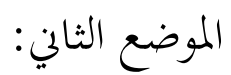
أسد علي وفن العدو أذلة............... العذا لعمرك فعل مولى الأشأم(99) الشاهد فن البيت هو قوله: لعمرك، وهو من مواضع حذف الخبر وجو"، كما يقول ابن مالك:

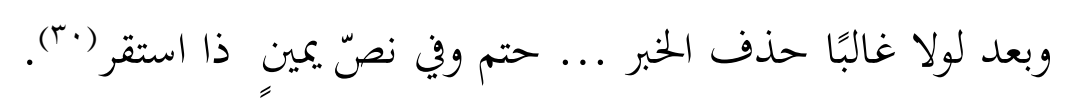
ذهب الجمهور إلى أن الخبر بعد لولا واجب الحذف مطلقًا بناء على أنه لا يكون إلا كو" مطلقًا، وإذا

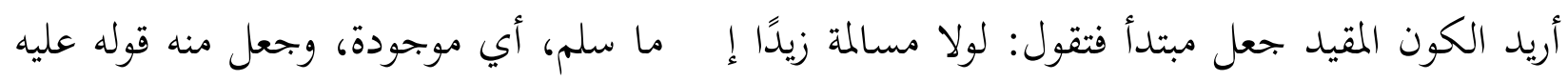

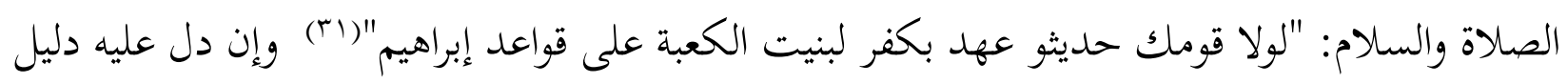
جاز إثباته وحذفه نحو لولا أنصار زيد حموه ما سلم، وجعل منه قول الشاعر:

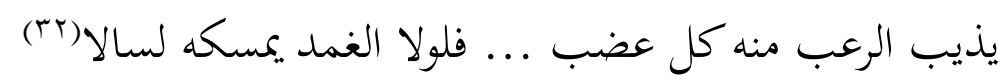

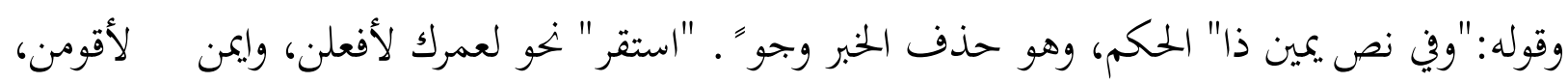
أي لعمرك قسمي (rr)، والجملة الاسمية معنزضة بين دوفي المبتدأ والخبر.

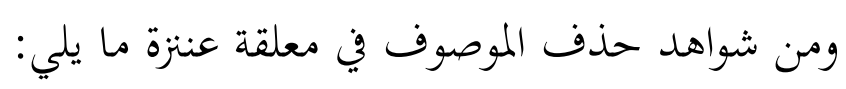

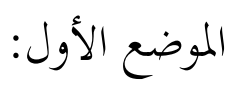

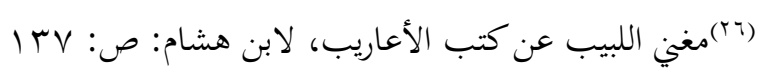

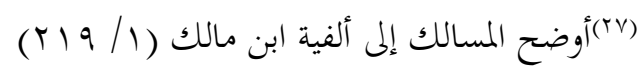

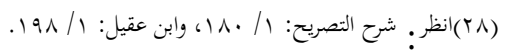

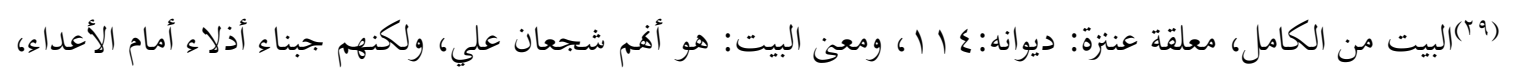

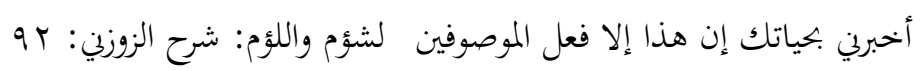

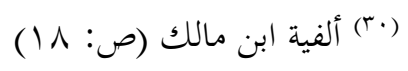

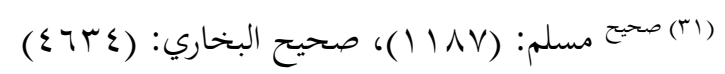

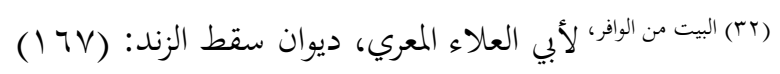

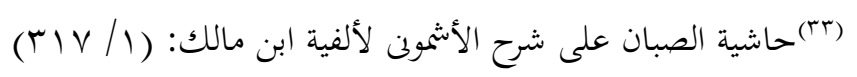


Faiz Syu'aib Adam : Deletion in Syndrome Compounds Perspective Antarah Bin Shaddad........

$$
\text { إلا رواكد بينهن خصائص.........بقية من نؤيها البحرنثم(ع) }
$$

الثاهد في البيت هو حذف الموصوف في قوله: إلا رواكد، وتقديره: إلا أ في رواكد، وهي الثابتة في موضع واحد، فنعت الموصوف نه بت في موضع واحد كالجامد الذي لا حركة له، دلالة على مالازمته ذلك الموضع، وقوله أيضًا: بينهن خصائص، صفة أخرى للموصوف المخذوف مركبة من جملة اسمية، والغرض من هذا الحذف هو الإيجار والاختصار، إذ المعنى مستفاد وهذا من طرق الاقتصاد اللغوي. الموضع الثاني:

$$
\text { أعياك رسم الدار لم يتكلم.............. تكلم كالأصم الأعجم }
$$

الشاهد في البيت هو حذف الموصوف فن قول الشاعر: كالأصم الأعجم، وتقدير المحذوف: كالرجل الأصم الأعجم، فهما صفتان من صفات الإنسان، فحذف الموصوف وأبقى الصفة وذلك لالاستغناء عنه.

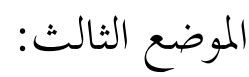
ولقد نزلت فلا تظي غيره..............منزلة المحب المكرم الشاهد في البيت هو في قوله: منزلة المب المكرم، ووجه الاستشهاد هو أن الشاعر حذف الموصوف واكتفى بذكر الصفة، وتقدير المخذوف: .منزلة الرجل المحب المكرم ، أو .منزلة الحبيب المحب المكرم، 6 فـ"الحب" هي الصفة الأولى للموصوف المخذوف، والمكرم هي الثانية، ودلالة هذا الحذف والغرض منه هو الاختصار.

ومن شواهد حذف المفعول به في معلقة عننزة بن شداد ما يلي: الموضع الأول:

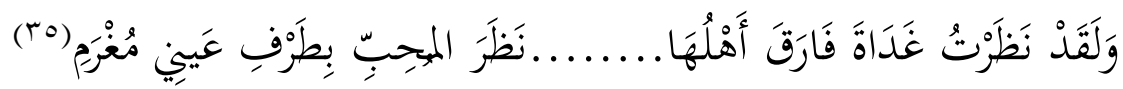
الشاهد في البيت هو قول الشاعر: نظرت، ووجه الاستشهاد هو أنه حذف مفعول به فعل "نظر" فلم يذكره، والجملة الفعلية جواب القسم لا محل لها من الإعراب، وكذلك القسم وجوابه كلام مستأنف لا حل له من الإعراب أيضًا، ودلالة هذا الحذف هو ضيق المقام، فالشاعر يشعر بضيق تج عن مفارقته حبيته، فلم يسع له الموضع لإلفصاح عن المفعول به لكراهة ذكره في نفس الشاعر.

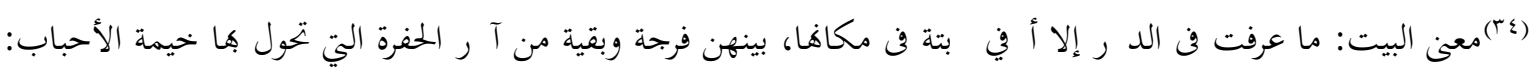

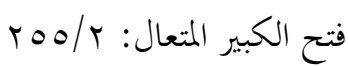
ا
} 


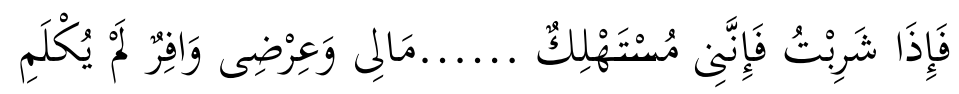
الشاهد في البيت هو قوله: وإذا شربت، ووجه الاستشهاد فيه هو حذف ورتر المفعول به لفعل شربك،

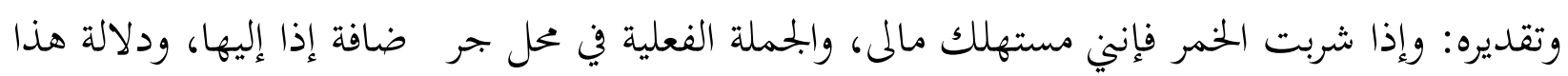
الحذف والغرض منه هو العلم به، وذلك لأن الشاعر ذكر الخمر في بيت قبل هذا، والبيت:

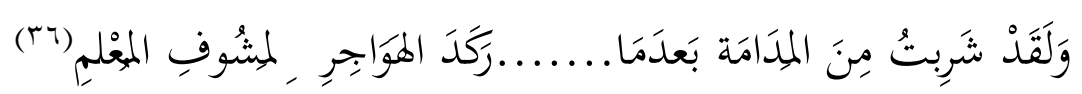

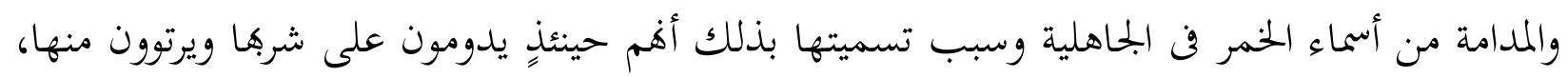

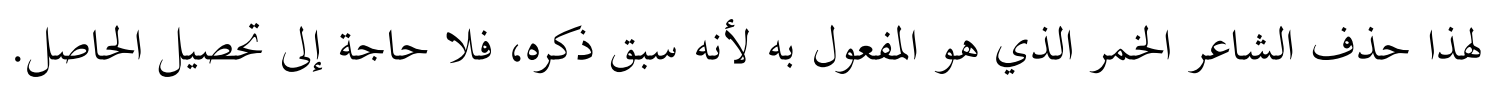
الموضع الثالث:

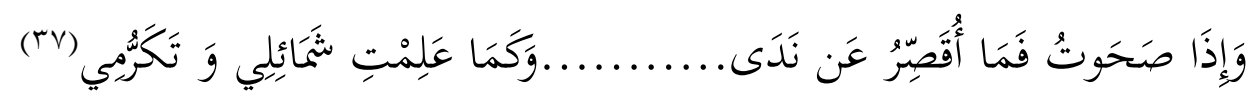

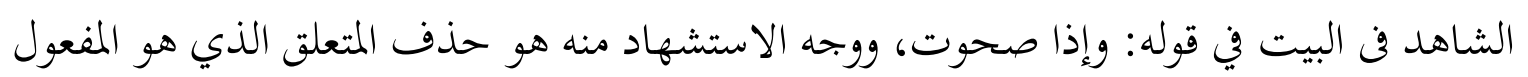
به، وتقديره: وإذا صحوت من سكري، فالجار والبحرور المخذوفان ومتعلقهما واقع في محل النصب مفعولا به، والغرض من حذفه هو الاختصار والإيجاز إذ المعنى واضح من تعلق الفعل محذوف ولخرون. ومن شواهد حذف المفعول المطلق في معلقة عننزة ما يلي:

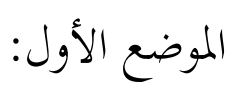

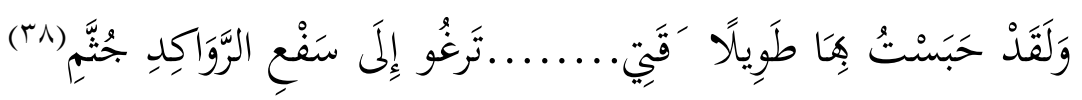

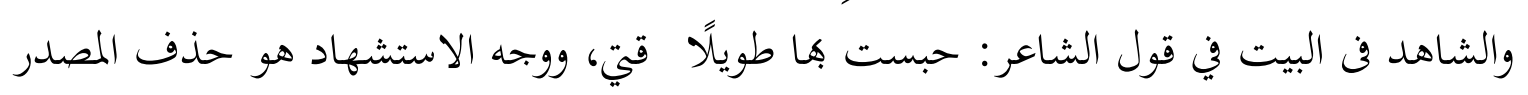

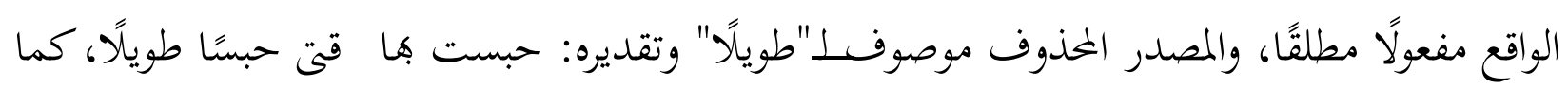
ظهر ذلك في معنى البيت، والغرض من هذا الحذف هو الاختصار.

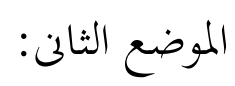

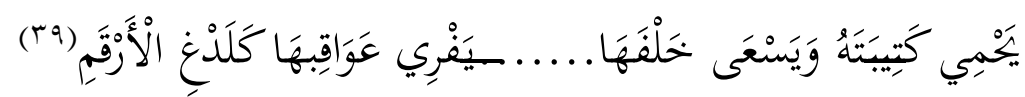

$$
\begin{aligned}
& \text { (2) n) } \\
& \text { I Y البيت من البسيط، لعنزة، ديوانه: (TV) }
\end{aligned}
$$

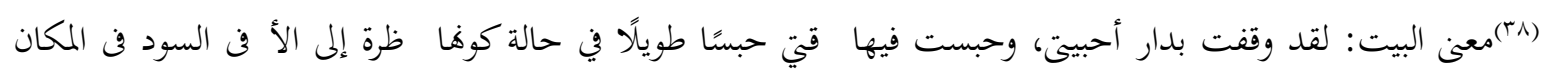
الذي كان يوضع عليه القدر عند الطبخ. 
الشاهد فن البيت في قول الشاعر: يفري عواقبها، ووجه الاستشهاد منه هو حذف المصدر الواقع

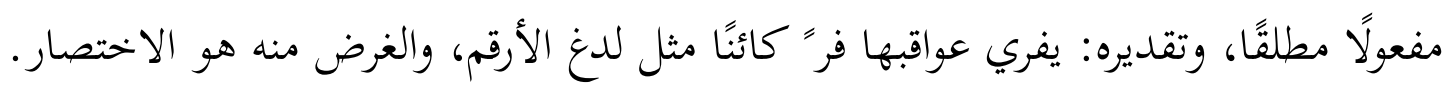
ومن شواهد حذف المنادى في معلقة عننزة قوله: الموضع الأول:

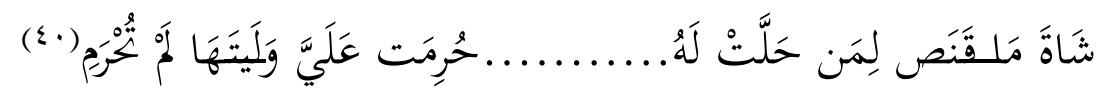

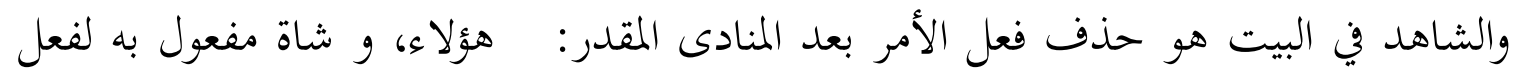
محذوف تقديره: هؤلاء اشهدوا شاة(1) ،ـفـ"نصب" شاة على المفعولية في تقدير الفعل المخذوف، والغرض منه الاختصار. ومن شواهده في معلقة عننزة بن شداد ما يلي:

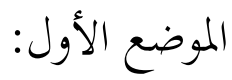

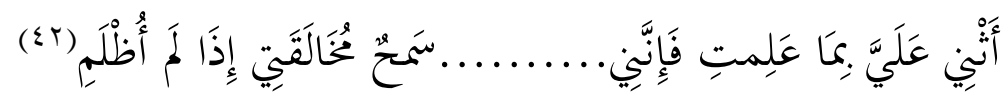
الشاهد في البيت في قوله: بما علمت، ووجه الاستشهاد منه هو حذف العائيد الواقع مفعولاً به في

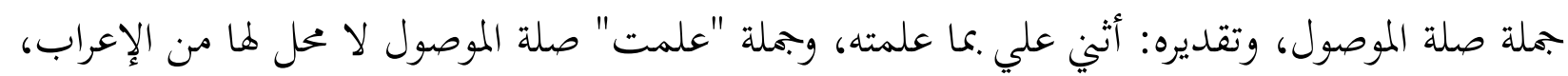
والغرض منه الاختصار.

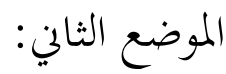

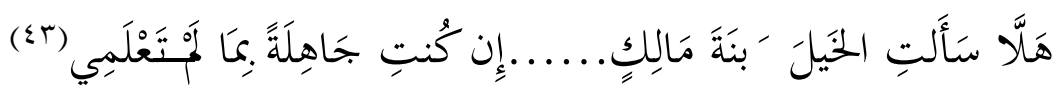

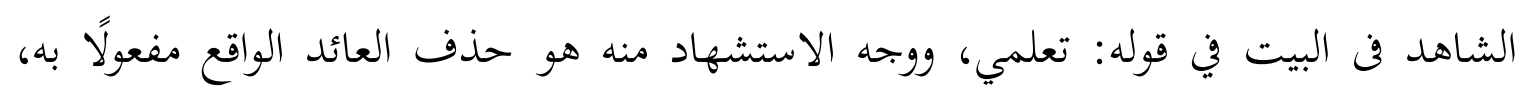
وتقديره: إن كنت جاهلة .ما لم تعلميه، وجملة "تعلمي" صلة الموصول لا محل لها من الإعراب، والغرض منه الإيجار والاختصار.

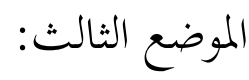

\footnotetext{
(.) قنص: القنص والقنيص: الصيد، العين:0/ 70، مادة: ق ن ص، معنى البيت: شاة صيدة لمن تمكن منها، وحلت له،

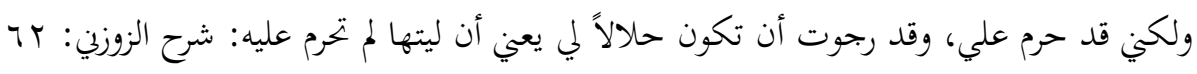$$
91:
$$$$
79 \text { (r) }
$$$$
\text { (r) المصدر السابق }
$$ 


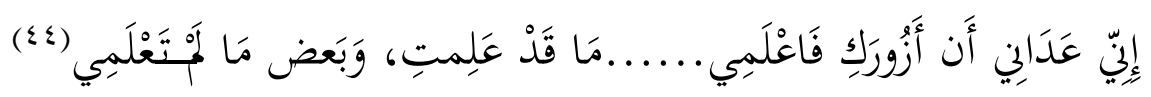

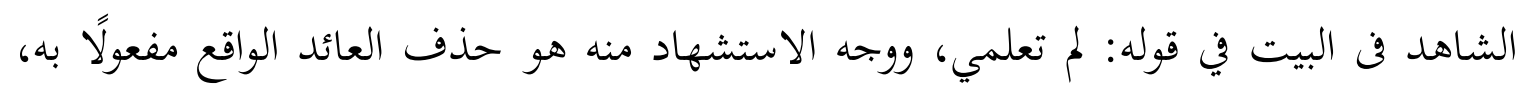
وتقديره: وبعض ما لم تعلميه، وجملة "عداني" في محل رفع خبر إن، وإن واسمها وخبرها جملة اسمية ابتدائية

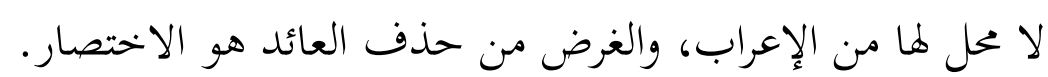
ومن شواهد حذف الفعل الماضي في معلقة عنزة بن شداد ما تئ تي:

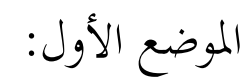

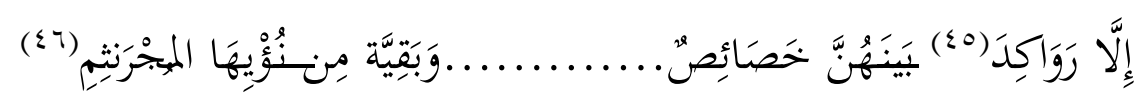
والشاهد في البيت هو حذف الفعل الماضي فن قول الشاعر: إلا رواكد، وتقدير الفعل المخدوف:

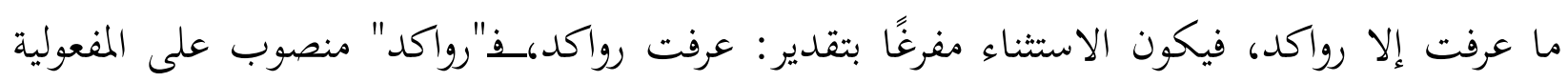
لفعل المخذوف، والغرض من هذا الحذف هو الاختصار. ومثال حذف فعل الأمر قول عننزة:

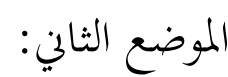

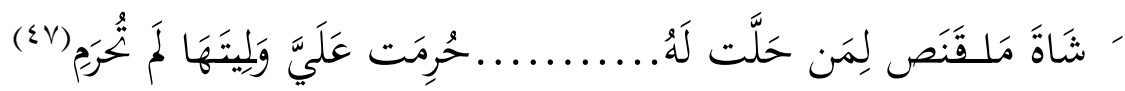

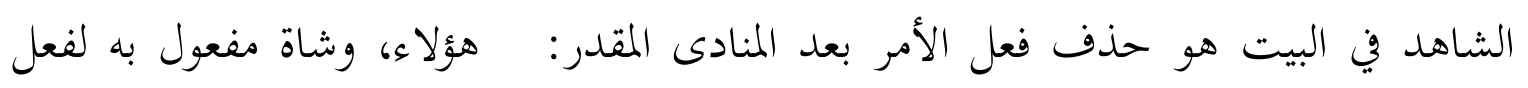

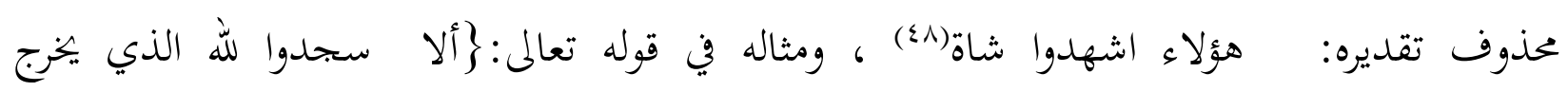

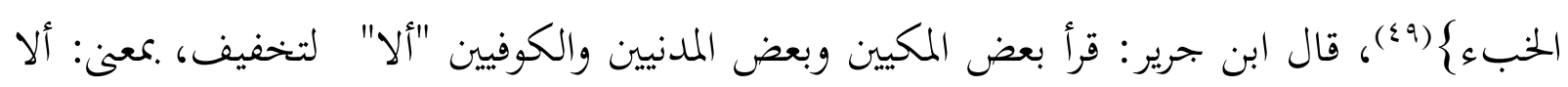

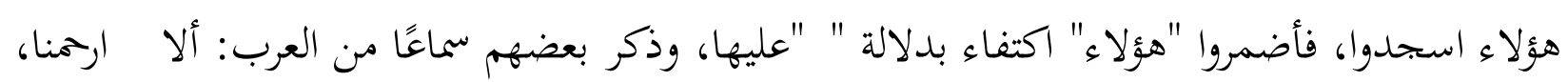

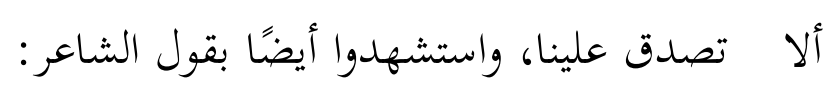

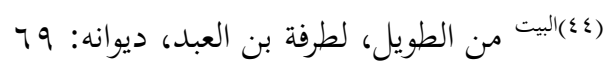

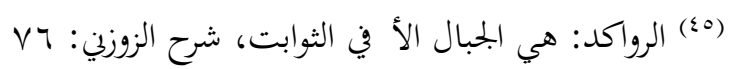

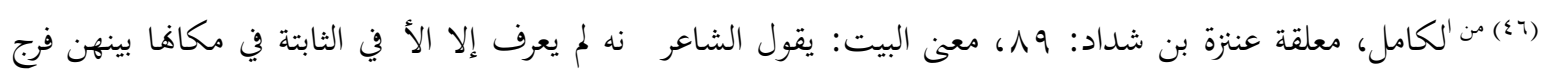

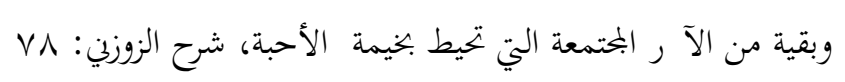

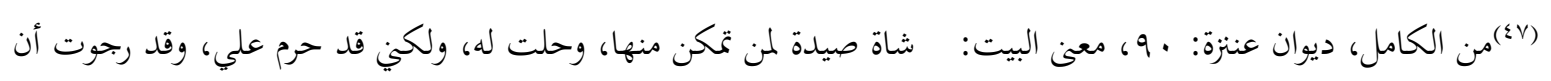

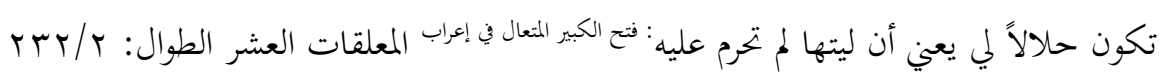

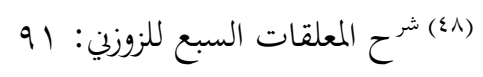

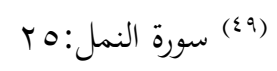




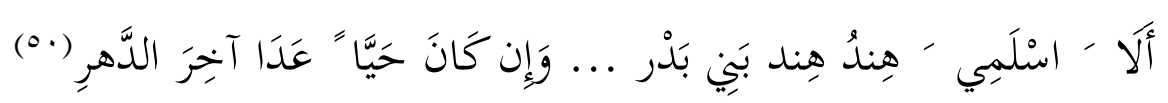

فعلى هذه القراءة اسجدوا في هذا الموضع جزم، ولا موضع لقوله "ألا"في الإعراب، وقرأ ذلك عامة قراء

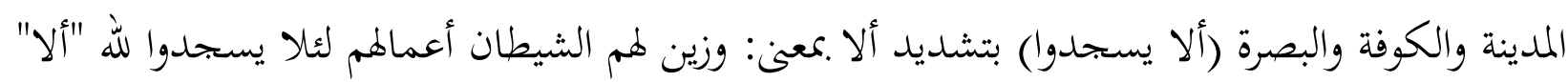

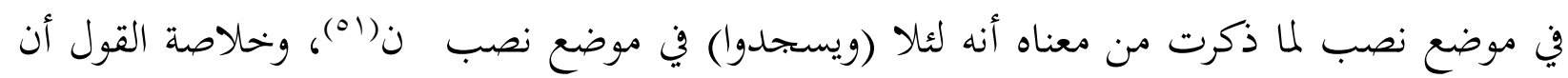
الشاهد في البيت هو حذف الفعل المقدر بعد النداء، والغرض من هذا الحذف هو الاختصار. ومن شواهد حذف حرف النداء في معلقة عننزة ما يلي:

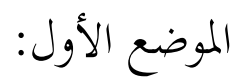

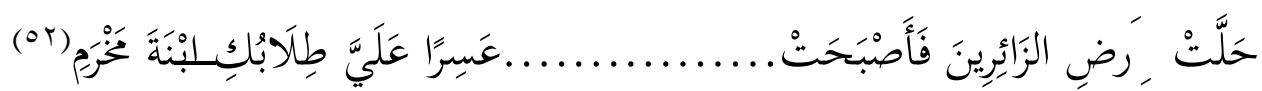

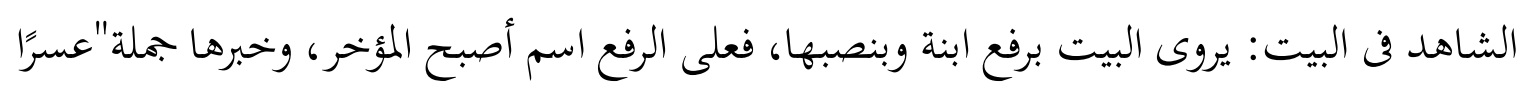
علي طلابك" وشاهدي في البيت على رواية النصب في قول الشاعر: ابنة خخرم، ووجه الاستشهاد فيه هو حذف حرف النداء، وتقديره: بنة مخرم، ولذلك نصب ابنة، لأنه مضاف، والمنادى المضاف حقه النصب، كما قال ابن مالك في الخلاصة:

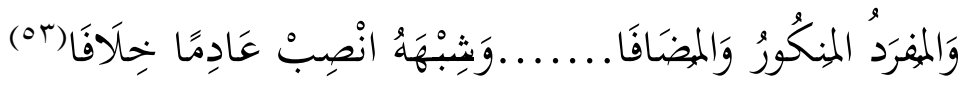
والغرض من هذا الحذف هو الاختصار وإخراج الكلام ع مقتضى الظاهر، لأن الشاعر نزل محبوبته منزلة القريب منه فحذف حرف النداء لهذه الدلالة. ومن شواهد حذف جواب لو في معلقة عننزة ما يلي:

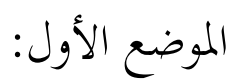

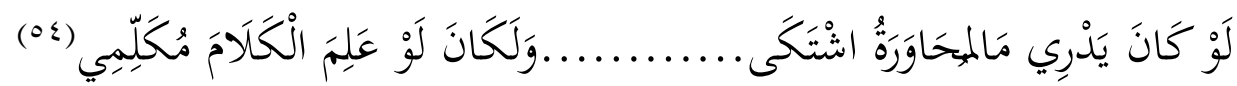

$$
\begin{aligned}
& \text { (م) (مالبيت من الطويل، نسبه في (اللسان: عدا) إلى الأغطل التغليي النصراني الشاعر الأموي }
\end{aligned}
$$

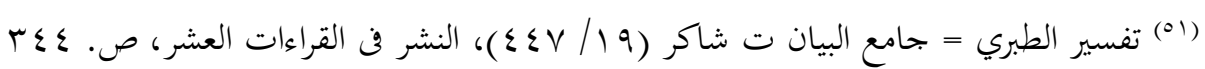

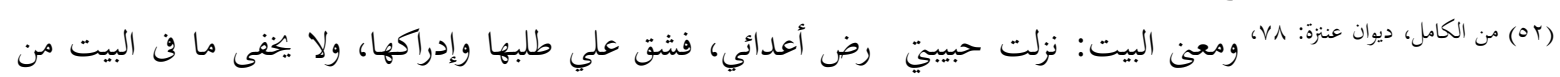

$$
\begin{aligned}
& \text { الالتفات، حيث التفت الشاعر من الغيبة إلى الخطاب. }
\end{aligned}
$$

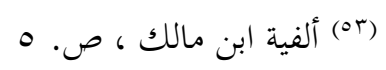

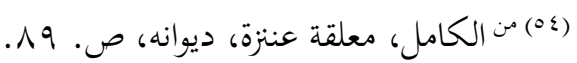


مفردات البيت واضحة المعنى، ومعني البيت أيضا واضح جدًّا، والشاهد في قوله: "لو علم الكلام"

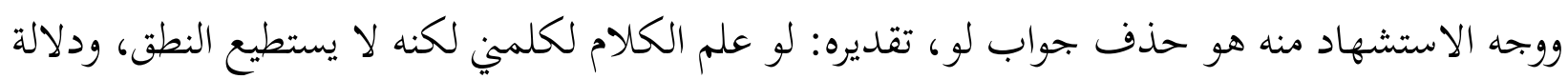
هذا الحذف والغرض منه هو الإيجاز والاختصار.

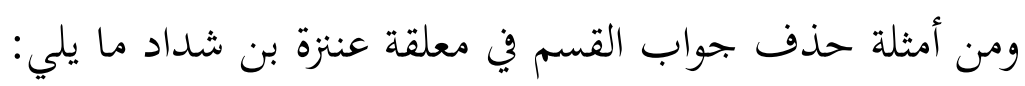

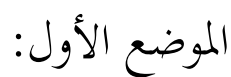

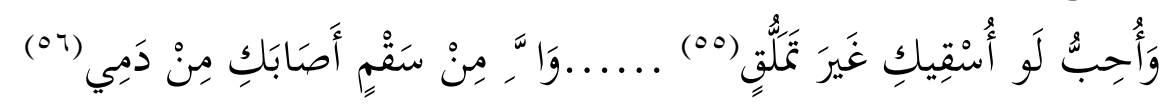

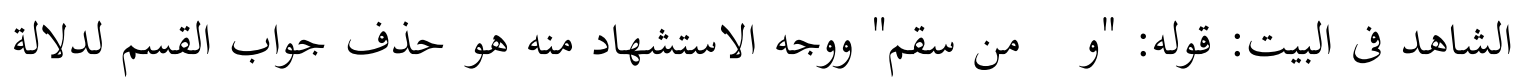

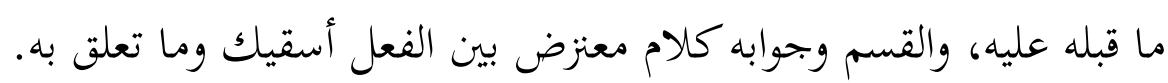
فهذه بعض من النماذج على حذف المركبات المتلازمة في هذه المعلقة الخاتمة

أختم هذا البحث بعون وقدرته بعد إيراد معلومات عن مفهوم الحذف النحوي بين المركبات المتلامة، ودت أن تكون الخاتمة كما يلي: مكانة الحذف والتقدير عمومًا لا تخفى على دارس اللغة العربية من حيث التقوية اللغوية، وخصوصًا ظاهرة الحذف فن المركبات المتلازمة كثيرة متنوعة. الحذف في هذه الأشكال من المركبات المتلازمة شيء كثر وقوعه وذلك لأفما شيئان لا يفنزقان، إن ظهر في اللفظ فهما، وإلا فلا بد من تقدير أحد المحذوفين. دوران البحث بين اللفظ والمعنى، لأن الحذف لا بد له من قرينة، وهذه القرينة تدور بين اللفظية والمعنوية,. قيامة القرائن اللفظية والمعنوية هي الدليل لوجود الحذف، لأن إدراك المحذوف ومعرفته هو السبيل للوصول إلى معنى الكلام الذي دخله الحذف إما حقيقة أو بحازًا. أغراض الحذف كثيرة في الكالام، لأن ذلك راجع إلى أذواق السامعين. مقاصد الكلام مبنية على ظواهر الذكر والحذف في الكلام، خصوصًا بين هذه المركبات.

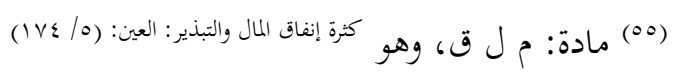

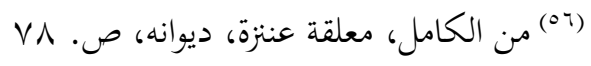




\section{Bibliografi}

Abdullah, Abu al-Baqo' bin Husain. At-Tibyan Fii 'irob al-Qur'an. Juz'un 2. Bairut: Isa al-Bab alHalbi. Duna Sanah.

Abdullah, Abu bin Bari al-Mishri. al-Tanbih wa al-Idhoh 'amman waqo'a Fii al-Shihah. Thobaqo 1. Mishro: Thohawi. 1981.

Ahmad, Abu Ja'far an-Nahhas bin Muhammad. 'Irobu al-Qur'an. Bairut: Darr al-Kitab al-Ilmiyah. 2000 .

Ahmad bin Abdurrohman bin Muhammad, Ibnu Madho, Ibnu Amir al-Lakhmi al-Qurthubi, dkk., al-Rodhu 'Ala al-Najah. Thobaqo 1. Mishro: Darr al-I'thishom. 1979.

Al-'abas, Abu, Syhabuddin, Ahmad bin Yusuf bin Abdul al-Daim. al-Dar al-Mushowin Fii Ulum al-Kitab al-Maknun. Damashqo: Darr al-Qolam. Duna as-Sanah.

Al-Andalusi, Abu Hayan. al-Tazyil wa al-Takmil Fii Syarhi Kitab al-Tashil. Thobaqo 1. Damashqo: Darr al-Qolam. Duna as-Sanah.

Al-Mukaram, Ali Abi. al-Hazfu wa al-Takdir. Thobaqo 1. Al-Qohiroh: Darr Ghorib. 2001.

Al-Qoli, Abu Ali wa Ismail bin Qosim. al-Bari'u Fii al-Lughah. Al-Juzz 1. Bairut: Darr alHadhoroh. 1975.

Amru Ibnu Ustman wa Abu Bashar (Sibawaih). al-Kitab. Thobaqo 3. al-Qohiroh: Maktabatu alKhoniji. 1988.

Arrohman, Abdul bin Abi Bakar. al-Itqon Fii Ulum al-Qur'an. Mishriyah: al-Haiah al-Mishriyah. 1974.

Arrohman, 'Abdul bin Muhammad. Al-Inshof Fii Masa'il al-Khilafi Baina al-Nahwaini: alBashoriyin wa al-Kuffiyin. Bairut: al-Maktab al-'ashriyah. 2003.

Habbatullah, Dhiyau addin Abu As-Sa'adat. Al-Amali al-Syajariyah. Bairut: Muassasah al-Risalah. 1984.

Ibrahim bin Sholih al-Hindud. al-Dhoruroh al-Syari'ah wa Mafhumuha Ladai al-Nahwiyyin Dirosah 'Ala Alfiyah ibn Malik. Thobaqo 3. Madinah al-Munawwaroh: al-Jami'ah alIslamiyah bil Madinah al-Munawwaroh. 2001.

Ismail, Abu Nash bin Hamad al-Jauhari. al-Shohah Tajjun al-Lughah wa Shohah al-Arobiyah. Thobaqo 4. Bairut: Darr al-Ilmu Lil Malayin. 1987.

Mahmud, Abu al-Qosim Ibnu Amru. al-Zamkhoshri Jarrullah. Thobaqo 3. Bairut: Darr al-Kitab al-Arobi. 1986.

Malik, Al-Ashma'i Abu Suaid Abdul. Al-Ashma'iyaat Ikhtibar al-Ashma'i. Mishro: Darr alMa'arif. 1993. 
Muhammad, Abu Hayyan bin Yusuf. Irtisyaf al-Dhorbu Min Lisan al-Arobi. al-Qohiroh: Maktabatu al-Khoniji. 1998.

Muhammad, Abu Abdullah Badruddin bin Abdullah. al-Burhan Fii 'Ulumi al-Qur'an. Thobaqo 1. Bairut: Darr Ihya al-Kutub al-Arobiyah. 1957.

Muhammad, Abu Abdullah bin Ahmad. Tafsir al-Qurthubi. Thobaqo 2. Al-Qohiroh: Darr alKutub al-Mishriah. 1964.

Muhammad bin Abdullah, Ibnu Malik al-Tho'i al-Jayani, Abu Abdullah, dkk,. Alfiyah Ibnu Malik. Juz 1. Mishro: Darr al-Ta'awun. Duna as-Sanah.

Muhammad, Abu Hayan. al-Bahru al-Muhith Fii al-Tafsir. Bairut: Darr al-Fikri. 2000.

Muhammad bin Abdurrohman bin Umar. al-Idhohu Fii 'Ulum al-Balaghah. Bairut: Darr al-Jail. Duna as-Sanah.

Muhammad bin Ismail Abu Abdullah. Shohihu al-Bukhori.Thobaqo 1. Bairut: Darr Thowaqu alNajah. 2001.

Muhammad Ibnu Yazid wa Abu al-Abas. al-Kamil Fii al-Lughah wa al-Adab. Thobaqo 3. AlQohiroh: Darr al-Fikr al-Arobi. 1997.

Muhammad, Majiduddin Abu Thohir ibn Ya'qub. al-Qomus al-Muhith. Thobaqo 8. Libnan: Muassasah al-Risalah Lii Thoba'ah wa al-Nashr wa al-Tauzi'. 2005.

Thohir, Muhammad bin Muhammad Muhammad al-Thohir. Al-tahriru wa al-Tanwinu. Tunis: adDarr al-Tunisiah. 1985.

Usman, Abu al-Fatah bin Jinni al-Musthofa. al-Khoshois. Thobaqo 4. Misroh: al-Haiah al-Mishriah al-‘Ammah Lil Kitab. Duna as-Sanah. 